\title{
Visible-light-induced addition of carboxymethanide to styrene from monochloroacetic acid
}

\author{
Kaj M. van Vliet, Nicole S. van Leeuwen, Albert M. Brouwer and Bas de Bruin
}

\author{
Full Research Paper \\ Address: \\ Van 't Hoff Institute for Molecular Sciences, Faculty of Science, \\ University of Amsterdam, Science Park 904, 1098 XH Amsterdam, \\ Netherlands \\ Email: \\ Bas de Bruin* - b.debruin@uva.nl \\ * Corresponding author \\ Keywords: \\ ATRA; catalysis; chloroacetic acid; lactone; photoredox
}

\author{
Beilstein J. Org. Chem. 2020, 16, 398-408. \\ doi:10.3762/bjoc. 16.38 \\ Received: 10 January 2020 \\ Accepted: 05 March 2020 \\ Published: 16 March 2020 \\ This article is part of the thematic issue "Advances in photoredox \\ catalysis". \\ Guest Editor: T. Noël \\ (c) 2020 van Vliet et al.; licensee Beilstein-Institut. \\ License and terms: see end of document.
}

\begin{abstract}
Where monochloroacetic acid is widely used as a starting material for the synthesis of relevant groups of compounds, many of these synthetic procedures are based on nucleophilic substitution of the carbon chlorine bond. Oxidative or reductive activation of monochloroacetic acid results in radical intermediates, leading to reactivity different from the traditional reactivity of this compound. Here, we investigated the possibility of applying monochloroacetic acid as a substrate for photoredox catalysis with styrene to directly produce $\gamma$-phenyl- $\gamma$-butyrolactone. Instead of using nucleophilic substitution, we cleaved the carbon chlorine bond by single-electron reduction, creating a radical species. We observed that the reaction works best in nonpolar solvents. The reaction does not go to full conversion, but selectively forms $\gamma$-phenyl- $\gamma$-butyrolactone and 4-chloro-4-phenylbutanoic acid. Over time the catalyst precipitates from solution (perhaps in a decomposed form in case of $f a c$-[ $\left.\operatorname{Ir}(\mathrm{ppy})_{3}\right]$ ), which was proven by mass spectrometry and EPR spectroscopy for one of the catalysts ( $N, N-5,10-\operatorname{di}(2-n a p h t h a l e n e)-5,10$-dihydrophenazine) used in this work. The generation of $\mathrm{HCl}$ resulting from lactone formation could be an additional problem for organometallic photoredox catalysts used in this reaction. In an attempt to trap one of the radical intermediates with TEMPO, we observed a compound indicating the generation of a chloromethyl radical.
\end{abstract}

\section{Introduction}

Monochloroacetic acid is an industrially important compound, with applications ranging from thickening agents (carboxymethyl cellulose, E466) [1,2], herbicides (2,4-dichlorophenoxyacetic acid), cosmetics (cocamidopropyl betaine), dyes (indigo

vat dye) [3], to pharmaceuticals (ibuprofen, glycine, malonates) [4] (see Figure 1). Many reactions with monochloroacetic acid have been published. The production of basic building blocks like glycine [5] (>600 000 tons/year in China in 2015) and 


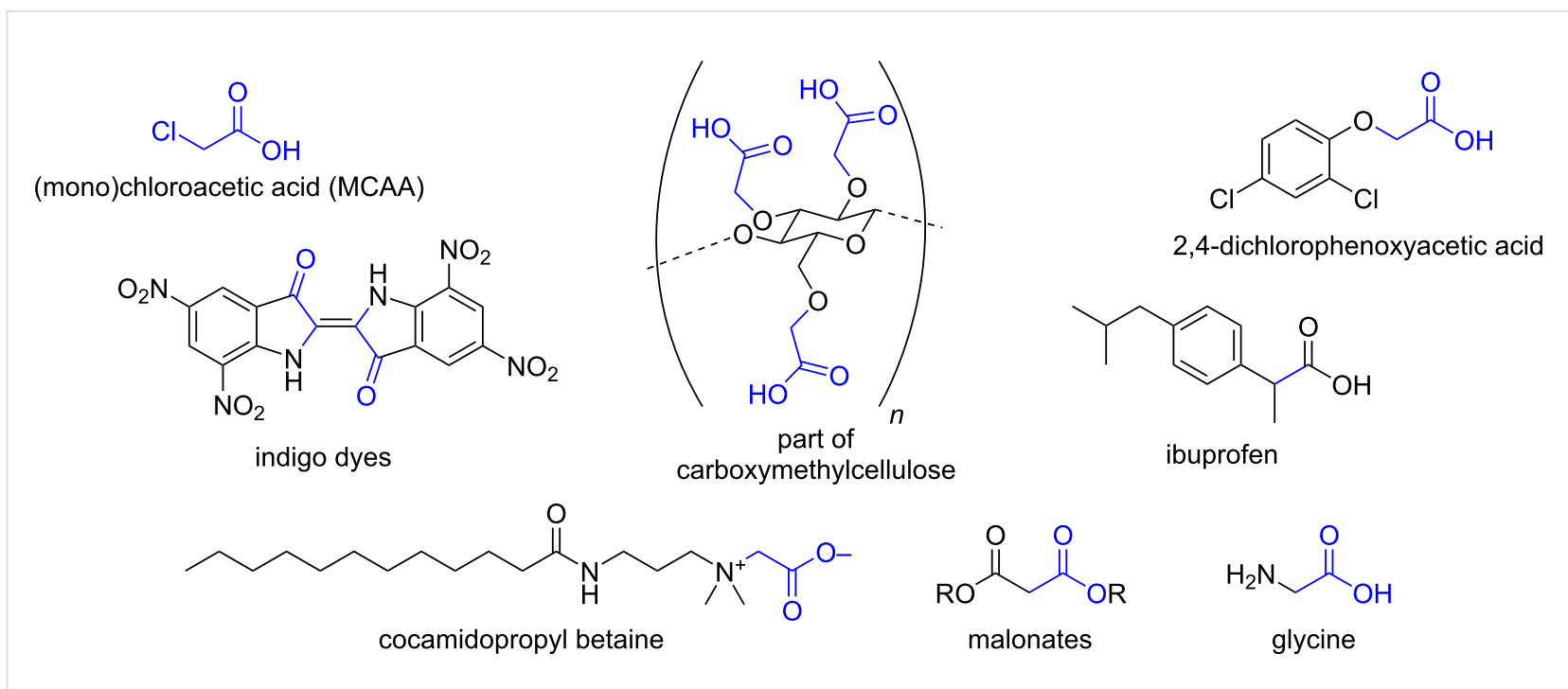

Figure 1: A part of the industry around monochloroacetic acid.

diethyl malonate from monochloroacetic acid show the value of this compound as a starting material. Many reactions with monochloroacetic acid, including the synthesis of glycine and diethyl malonate, are based on nucleophilic substitution of the chlorine [6-10].

In an attempt to find new synthetic applications of monochloroacetic acid we turned our attention to photoredox catalysis. We were inspired by the rebirth of visible light photoredox catalysis, induced by the work of Yoon, Stephenson and MacMillan [11]. By selective excitation of an organic or organometallic dye by visible light a species is formed that can act as a single-electron oxidant and single-electron reductant. In this way reactive radical intermediates can be formed catalytically in situ, resulting in reactivity different from common twoelectron pathways. Photoredox catalysis reactivity is very different from traditional redox reactions, and the same reactivity cannot be achieved by stoichiometric addition of both a reductant and an oxidant to a reaction mixture (as that would lead to a rapid redox reaction between the oxidant and the reducing agent instead of converting the substrate). Excitation of the photocatalyst, on the other hand, allows continuous formation of low concentrations of both oxidized and reduced radical forms of the substrate(s), and the excited catalysts (and/or their oxidized/ reduced forms) can perform both opposed redox events before returning to their original oxidation state for re-excitation. If no substrate is encountered during the lifetime of the excited state the ground state is typically regenerated.

Such photogenerated radical intermediates can be useful for the formation of new $\mathrm{C}-\mathrm{C}$ bonds. Previous works from our group presented cobalt-catalyzed radical cyclization and carbonyla- tion reactions [12-16]. Photoredox catalysis provides a way to generate radical intermediates from simple organic molecules by single-electron redox processes. Single-electron oxidation can produce carbon-centered radicals from substrates such as amines [17], alkenes [18], and carboxylates [19], or by hydrogen-atom transfer to an oxidatively formed thiolate radical [20]. Single-electron reduction produces carbon-centered radicals from, for example, aryl nitriles [21], carbonyl or imine species [22], iodonium or diazonium salts [23], or halide species [24].

The formation of radicals from halide species by photoredox catalysis has been widely studied. It has been applied as a mild method for the dehalogenation of several compounds [25-27]. In the light of photoredox catalytic $\mathrm{C}-\mathrm{C}$ bond formation, its application in the field of atom transfer radical addition (ATRA) reactions is very important. Remarkably, this type of $\mathrm{C}-\mathrm{C}$ bond formation became only popular in 2011, while the first example was already published by Barton in 1994 [28].

Recently, Kokotos and co-workers published a visible light photoredox catalyzed lactone formation from iodoacetic acid and alkenes [29] (Scheme 1). In addition, it has been shown that monochloroacetic acid can be reduced by hydrated electrons [30,31]. The group of Goez developed a strategy for the photoredox generation of hydrated electrons and applied that for the dehalogenation of monochloroacetic acid [32,33]. However, to the best of our knowledge, a photoredox catalyzed application of monochloroacetic acid without using a sacrificial electron donor is not known. Interestingly, monochloroacetic acid also contains a carboxyl group that could perhaps be oxidatively decarboxylated to generate a chloromethyl radical. In this 


$$
\text { S Org. Lett. 2018, 20, 36 [29] }
$$

Scheme 1: Redox based activation of haloacetic acid.

study, we investigated the possibility of redox neutral, visible light photoredox catalyzed $\mathrm{C}-\mathrm{C}$ bond formation with monochloroacetic acid.

\section{Results and Discussion}

First, we used cyclic voltammetry to determine the oxidation potential $\left(E_{\mathrm{Ox}}\right)$ of monochloroacetic acid in acetonitrile (Figure 2). This way it could be verified, if monochloroacetic acid can quench the excited state of one of the common photoredox catalysts. In Figure 1 the cyclic voltammogram of monochloroacetic acid is shown. One can see the onset potential for the reduction of monochloroacetic acid at $-1.5 \mathrm{~V}$ vs $\mathrm{Fc} / \mathrm{Fc}^{+}$. The two photoredox catalysts, $f a c-\operatorname{Ir}(\mathrm{ppy})_{3}\left(E^{*}{ }_{\mathrm{ox}}=\right.$
$-2.1 \mathrm{~V}$ vs $\left.\mathrm{Fc} / \mathrm{Fc}^{+}\right)$[34] and $\left[\mathrm{Cu}(\mathrm{dap})_{2}\right] \mathrm{Cl}\left(E^{*}{ }_{\mathrm{ox}}=-1.8 \mathrm{~V}\right.$ vs $\mathrm{Fc} / \mathrm{Fc}^{+}$) are strong enough reducing agents in their excited states to be oxidatively quenched by monochloroacetic acid. Based on these data, we concluded that the visible-light-promoted reductive photoredox $\mathrm{C}-\mathrm{C}$ bond coupling reaction with monochloroacetic acid should be possible.

As such, we chose $f a c-\left[\operatorname{Ir}(\mathrm{ppy})_{3}\right]$ and $\left[\mathrm{Cu}(\mathrm{dap})_{2}\right] \mathrm{Cl}$ for the photoredox reaction between monochloroacetic acid and styrene in acetonitrile under an atmosphere of $\mathrm{N}_{2}$ to form the lactone 5-phenyldihydrofuran-2(3H)-one (and $\mathrm{HCl}$ ) or the acid 4-chloro-4-phenylbutanoic acid via an ATRA reaction (Scheme 2). The photoredox catalysts are excited by using blue

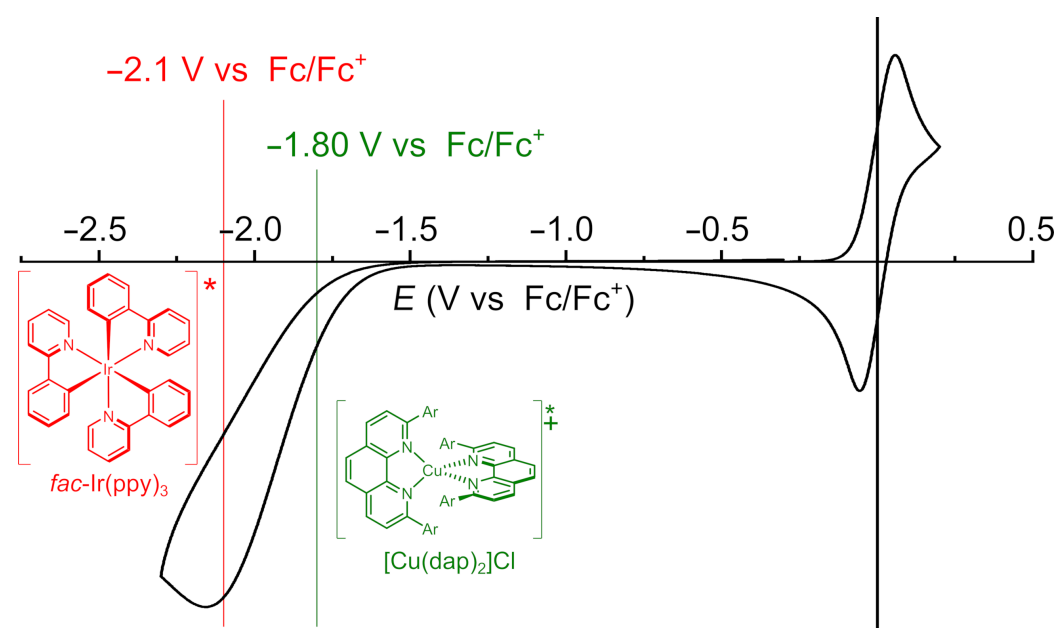

Figure 2: Cyclic voltammogram of monochloroacetic acid and ferrocene with $0.1 \mathrm{M}[\mathrm{TBA}][\mathrm{PF} 6]$ in $\mathrm{MeCN}$. The potential is referenced to the $\mathrm{Fc} / \mathrm{Fc}^{+}$ redox couple $(0 \mathrm{~V})$. The excited state reduction potentials of two different reducing photoredox catalysts (in red and green) are shown in the figure.

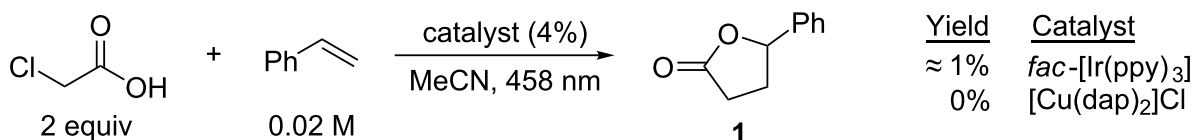


LEDs with a peak excitation of $458 \mathrm{~nm}$ (see the experimental section for a detailed description) which is sufficient for the excitation of both complexes. For $\left[\mathrm{Cu}(\mathrm{dap})_{2}\right] \mathrm{Cl}$, no product was observed, but with $f a c$-[ $\left[\operatorname{Ir}(\mathrm{ppy})_{3}\right]$ we could observe the desired lactone, albeit in small amounts.

After these unsatisfying results we focused on the formation of the carboxymethanide radical. We attempted trapping the radical by replacing styrene with TEMPO (2,2,6,6-tetramethylpiperidin-1-yl)oxyl). However, GC-MS analysis indicated full conversion of TEMPO to the adduct resulting from a radical coupling between a cyanomethanide radical and TEMPO (Scheme 3 ) for the highly reducing $\left[\operatorname{Ir}(\mathrm{ppy})_{3}\right](-1.73 \mathrm{~V}$ vs SCE in its excited state [35]). The weak C-H bond of acetonitrile (93.0 kcal mol${ }^{-1}$ ) compared to the $\mathrm{C}-\mathrm{H}$ bond strength of a carbonyl $\alpha-\mathrm{C}-\mathrm{H}$ bond $\left(94.1 \mathrm{kcal} \mathrm{mol}^{-1}\right)$ resulted in formation of 2 (2,2,6,6-tetramethylpiperidin-1-yl)oxyacetonitrile (compound 2; Scheme 3) [36].

Hence, to avoid the reaction with the solvent, we applied solvents with stronger $\mathrm{C}-\mathrm{H}$ bonds (see Table 1). DMF and DMSO are used frequently in the field of photoredox catalysis, but the use of these solvents did not lead to formation of the desired product either (Table 1, entries 2 and 3), using fac-[Ir(ppy) 3$]$ or $\left[\mathrm{Cu}(\text { dap })_{2}\right] \mathrm{Cl}$ as the photosensitizer. Because the use of polar solvents did not lead to the desired reactivity, we turned to non-<smiles>CC1(C)CCCC(C)(C)N1[O]</smiles>

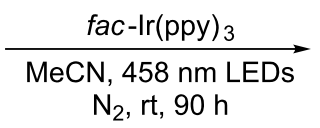<smiles>[Z]C1(C)CCCC(C)(C)N1OCC#N</smiles>

Scheme 3: The photoredox reaction of TEMPO with monochloroacetic acid catalyzed by fac-[ $\left[\mathrm{Ir}(\mathrm{ppy})_{3}\right]$

Table 1: Conditions screening for the photoredox catalyzed reaction between monochloroacetic acid and styrene. ${ }^{\mathrm{a}}$

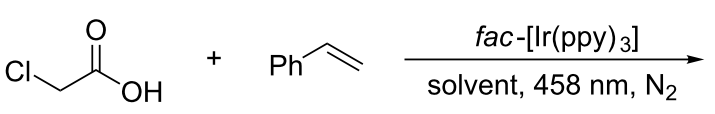<smiles>O=C1CCC(c2ccccc2)O1</smiles>

1<smiles>O=C(O)CCC(Cl)c1ccccc1</smiles>

\begin{tabular}{lllll}
\hline Exp. & Cat. loading & Solvent & ClAcOH (equiv) & Yield (1:3) \\
\hline 1 & $4 \%$ & MeCN & 2 & $\approx 1 \%(1: 0)$ \\
2 & $4 \%$ & DMF & 2 & $<1 \%$ \\
3 & $4 \%$ & DMSO & 2 & $<1 \%$ \\
4 & $4 \%$ & benzene & 2 & $49 \%(1: 3.0)$ \\
5 & $4 \%$ & trifluoromethylbenzene & 2 & $13 \%(1: 4.4)$ \\
6 & $4 \%$ & chlorobenzene & 2 & $22 \%(1: 3.3)$ \\
8 & $4 \%$ & toluene & 2 & $27 \%(1: 4.7)$ \\
9 & $4 \%$ & DCE & 2 & $11 \%(1: 1.3)$ \\
10 & $10 \%$ & benzene & 2 & $84 \%(1: 4.3)$ \\
11 & $3 \%$ & benzene & 2 & $34 \%(1: 2.8)$ \\
12 & $2 \%$ & benzene & 2 & $32 \%(1: 2.2)$ \\
13 & $1 \%$ & benzene & 2 & $18 \%(1: 1.3)$ \\
14 & $0.5 \%$ & benzene & 2 & $<1 \%$ \\
15 & $4 \%$ & benzene & 0.5 & $46 \%(1: 2.8)$ \\
16 & $4 \%$ & benzene & 3 & $43 \%(1: 3.3)$ \\
17 & $4 \%$ & benzene & 4 & $45 \%(1: 3.1)$ \\
18 & $4 \%$ & benzene & 5 & $46 \%(1: 2.8)$ \\
$19^{b}$ & $4 \%$ & benzene & 2 & $11 \%(1: 1.2)$ \\
20 & $0 \%$ & benzene & 2 & - \\
$21^{c}$ & $4 \%$ & benzene & 2 & - \\
\hline
\end{tabular}

aA mixture of styrene $(0.02 \mathrm{M})$, monochloroacetic acid and fac-[ $\left.\operatorname{lr}(\mathrm{ppy})_{3}\right]$ in solvent $(2 \mathrm{~mL})$ was irradiated overnight under a $\mathrm{N}_{2}$ atmosphere with $458 \mathrm{~nm}$ LEDs. The yield was determined by ${ }^{1} \mathrm{H}$ NMR spectroscopy with trimethoxybenzene as external standard. ${ }^{\mathrm{b}} 60 \mathrm{~W}$ fluorescent light bulb. ${ }^{\mathrm{C}} \mathrm{In}$ the dark. 
polar solvents. Since $\left[\mathrm{Cu}(\mathrm{dap})_{2}\right] \mathrm{Cl}$ is insoluble in nonpolar solvents, we continued with the more reducing $f a c$ - $\left[\operatorname{Ir}(\mathrm{ppy})_{3}\right]$ photocatalyst. The choice of benzene as a solvent led to a significant formation of the desired lactone, according to GC-MS analysis. The ${ }^{1} \mathrm{H}$ NMR and mass spectra of the crude reaction mixture also demonstrated the formation of the ATRA product 4-chloro-4-phenylbutanoic acid. The two products were obtained in a combined yield of $49 \%$ (Table 1, entry 4 ). A further screening of nonpolar solvents did not lead to any significant increase of the yield or selectivity (Table 1, entries 5-9).

The reduction of catalyst loading resulted in a lower yield and a lower selectivity for the acid compound 3 (Table 1, entries 10-14). The products indicate an oxidative quenching of the photoredox catalyst by reduction of the carbon chlorine bond of monochloroacetic acid. Varying the stoichiometry of substrates also did not lead to any improvement of the yield (Table 1, entries $15-18)$, most likely because the $f a c-\left[\operatorname{Ir}(\text { ppy })_{3}\right]^{+}$complex $(+0.77 \mathrm{~V}$ vs SCE) is unable to oxidize styrene sufficiently. In the absence of the photoredox catalyst or light, the reaction does not take place (Table 1, entries 19 and 20).

Notably, during the reaction, the bright yellow color of the solution resulting from the absorption of the catalyst disappears and an insoluble precipitate is formed. The use of $\mathrm{C}_{6} \mathrm{D}_{6}$ as a solvent allowed us to directly measure the ${ }^{1} \mathrm{H}$ NMR spectrum of the crude reaction mixture. The presence of both monochloroacetic acid and styrene in this mixture is another indication that the catalyst had decomposed or precipitated from the solution before consumption of all substrate. Unfortunately, because of a lack of solubility, we were unable to analyze the precipitate. We also applied organic photoredox catalysts [37]. Miyake and co-workers have introduced highly reducing organic photoredox catalysts [38-43]. The use of 5,10-di(naphthalen-2yl)-5,10-dihydrophenazine or 3,7-di(biphenyl-4-yl)-10-(naphthalen-1-yl)-10H-phenoxazine instead of $\left[\operatorname{Ir}(\mathrm{ppy})_{3}\right]$ as the photoredox catalyst had no beneficial effect on the yield or conversion, and also led to the formation of a precipitate. However, the precipitate that was formed when the organic dye 5,10-di(naphthalene-2-yl)-5,10-dihydrophenazine was used proved to be soluble in DMSO, allowing us to characterize the material. After we discovered that the redissolved precipitate was NMR-silent, a room temperature EPR spectrum was recorded (Figure 3). The multiplicity in this spectrum is in agreement with formation of the 1e-oxidized form of the organic photocatalyst, showing hyperfine interactions with two equivalent nitrogen nuclei $\left(g_{\text {iso }}=2.0032 ; A^{\mathrm{N}_{\text {iso }}}=18.6 \mathrm{MHz}\right)$. The HRMS of this species showed the mass of the catalyst, thus confirming that the oxidized catalyst precipitates as a salt from solution when using benzene as a solvent.

Based on the formation of the cation of the photoredox catalyst, we believe that after oxidative quenching the catalyst is not fully reduced back to the neutral complex, accumulates in solution and as a result precipitates as chloride salt (with $\mathrm{Cl}^{-}$stemming from the substrate). We assume that the same happens when using the $f a c$-[ $\left[\operatorname{Ir}(\text { ppy })_{3}\right]$ photocatalyst (vide supra; although for the precipitate generated from this catalyst we were

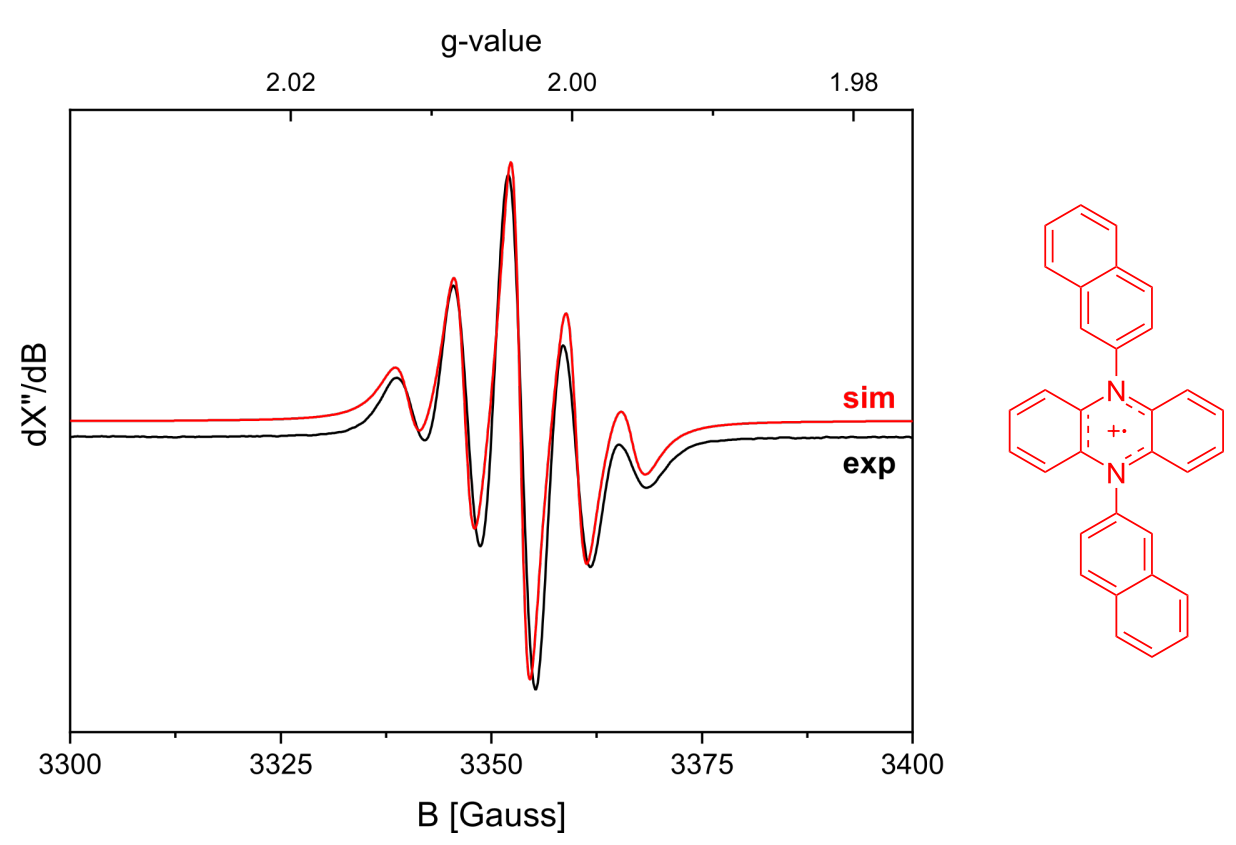

Figure 3: EPR spectra measured (black) and simulated (red) based on the structure of the oxidized photoredox catalyst shown on the right. 
unable to redissolve the solids for characterization). Also here the catalyst is likely to precipitate as $\left[\operatorname{Ir}(\mathrm{ppy})_{3}\right] \mathrm{Cl}$, but for this photocatalyst additional deactivation pathways could also play a role. For every lactone product that is formed, $\mathrm{HCl}$ is generated and in the case of $f a c$-[Ir(ppy $\left.)_{3}\right]$, the acid could potentially cause protodemetalation. This protodemetalation could be even more pronounced in the excited state (which is after all a metalto-ligand charge-transfer state). Therefore, we focused on methods to trap the $\mathrm{HCl}$ from solution (see Table 2). An addition of 2,6-lutidine as a base leads to a lower conversion. Although the addition of a base is an efficient method to remove $\mathrm{HCl}$, deprotonation of monochloroacetic acid leads to an anionic species that is harder to reduce. However, the use of 2,6-lutidine gave a $32 \%$ yield. This could be caused by the reduced Brønsted base strength in apolar solvents. Thus, to avoid using a base that deprotonates monochloroacetic acid, we added sodium chloroacetate to capture $\mathrm{HCl}$ from the reaction. However, under these conditions the desired product was not formed at all. Addition of $[\mathrm{Ag}] \mathrm{PF}_{6}$ to remove the chloride and solubilize the oxidized photocatalyst also did not lead to any product formation. $[\mathrm{Ag}] \mathrm{PF}_{6}$ is poorly soluble in benzene and the $\mathrm{Ag}^{+}$ion is likely to act as an oxidizing agent quenching the excited state of the photocatalyst. Another additive we tried was tetrabutylammonium hexafluorophosphate, thought to precipitate [TBA]Cl and to keep $\left[\operatorname{Ir}(\mathrm{ppy})_{3}\right]^{+}$in solution as the $\mathrm{PF}_{6}{ }^{-}$salt. However, performing the reaction in the presence of $[\mathrm{TBA}] \mathrm{PF}_{6}$ led to a decreased yield. The use of diphenylurea to trap $\mathrm{Cl}^{-}$did not lead to a significant increase of the reaction yield either. In addition, sodium iodide and tetrabutylammonium iodide were tested in an attempt to form an iodo intermediate which was expected to cyclize more easily to the lactone [44]. However, the lack of solubility of these reagents in benzene likely hampered nucleophilic substitution and resulted in very low yields. Sodium ascorbate was also added to investigate whether a sacrificial electron donor could increase the yields, but this was not observed. Interestingly, the reaction with sodium ascorbate favored the formation of lactone $\mathbf{1}$ over linear acid $\mathbf{3}$. The exact reason for this behavior is not clear, but perhaps ascorbate acts as a weak base favoring lactone formation without deprotonating monochloroacetic acid.

In another attempt to avoid the formation of $\mathrm{HCl}$ we applied methyl chloroacetate. Hereby the formation of the lactone is inaccessible and $\mathrm{HCl}$ cannot be formed. However, when using this substrate only $13 \%$ of the ATRA product were observed. Hence, there thus seems to be a positive effect of the acid on the activation of the $\mathrm{C}-\mathrm{Cl}$ bond. The precise mechanism of this reductive cleavage is currently unclear. Besides the direct reduction of a carbon chlorine bond by electron transfer into the $\mathrm{C}-\mathrm{Cl}$ antibonding orbital (Scheme 4A), the same intermediate can be formed by fragmentation of an $\alpha$-haloketyl radical (Scheme 4B). The acidic environment could lead to easier formation of this ketyl radical. Intuitively, pathway B seems most probable.

The reaction in benzene forms mainly the acid product 3 originating from an ATRA reaction. We propose that this product is formed by radical propagation followed by a mechanism first

Table 2: Additive screening for the photoredox reaction between styrene and monochloroacetic acid. ${ }^{a}$

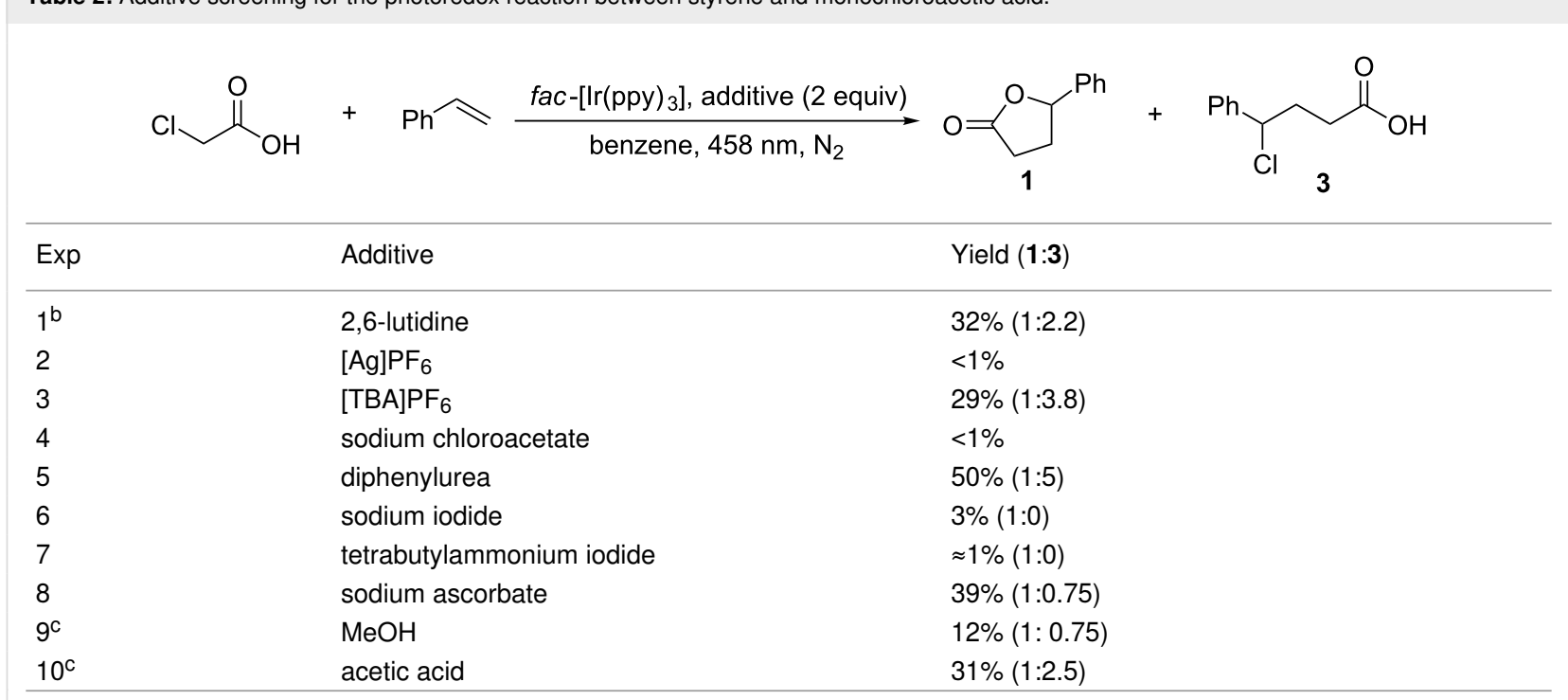

${ }^{a} \mathrm{~A}$ mixture of styrene $(0.02 \mathrm{M})$, monochloroacetic acid (2 equiv), fac-[Ir(ppy) 3 ] and an additive (2 equiv) in benzene (2 $\left.\mathrm{mL}\right)$ was irradiated overnight under an $\mathrm{N}_{2}$ atmosphere with $458 \mathrm{~nm}$ LEDs. The yield was determined by ${ }^{1} \mathrm{H}$ NMR spectroscopy with trimethoxybenzene as external standard. b 0.5 equiv of monochloroacetic acid were used. ${ }^{C}$ Additive as a cosolvent (10\%). 
A)<smiles>CC(=O)O</smiles>

B)

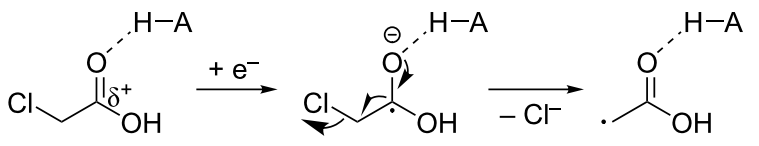

Scheme 4: Two possible acid-assisted, reductive activation pathways of monochloroacetic acid ( $\mathrm{A}-\mathrm{H}=\mathrm{acid})$.

found by Kharasch and co-workers, where the benzyl radical formed after addition of the generated $\alpha$-carbonyl radical abstracts a chloride from monochloroacetic acid to obtain the product and propagates the reaction [45]. In situ IR experiments show an exponential grow for product formation, which is indeed indicative of a radical propagation mechanism (see Supporting Information File 1). In acetonitrile, a small amount of lactone was formed and no desired acid. Therefore, we investigated the effect of polarity on the selectivity of the reaction by mixing acetonitrile with benzene (Table 3 ). Based on the result with pure acetonitrile as a solvent (Scheme 2 and Scheme 3), we expected a lower yield with higher concentrations of acetonitrile. Indeed, the yield decreased with increasing amounts of acetonitrile. On the other hand, the selectivity for the formation of the lactone increased by adding more acetonitrile [46].

To evaluate if $\gamma$-phenyl- $\gamma$-butyrolactone (1) can be formed from 4-chloro-4-phenylbutanoic acid (3) in benzene we reacted irradiated mixtures of $\mathbf{3}$ with either the photoredox catalyst, mono- chloroacetic acid or both. We did not see any formation of the lactone (1) after irradiating the mixtures overnight with $458 \mathrm{~nm}$ LEDs. Therefore, it is unlikely that in benzene direct conversion from 3 to 1 plays any significant role under the applied reaction conditions. The photoredox activation of monochloroacetic acid leads to the formation of precipitate during the reaction (see Figure 4), again indicating catalyst precipitation/ deactivation.

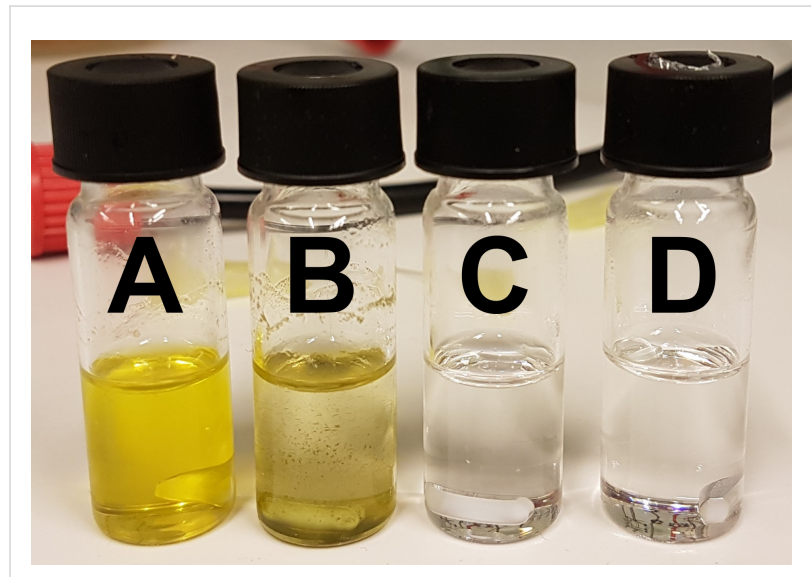

Figure 4: Reaction mixtures after overnight irradiation of (A) 4-chloro4-phenylbutanoic acid (3) and $\operatorname{fac}$ - $\left[\operatorname{Ir}(\mathrm{ppy})_{3}\right]$; (B) 3, fac-[ $\left.\operatorname{lr}(\mathrm{ppy})_{3}\right]$ and monochloroacetic acid; (C) $\mathbf{3}$; (D) $\mathbf{3}$ and monochloroacetic acid. In none of the vials lactone 1 was formed.

Works in the group of Noël and others have revealed that flow chemistry can increase the rate and yield of photoredox reactions significantly [47-53]. According to the law of Lambert-Beer, only the outer shell of a batch reactor (vial or Schlenk flask) is excited efficiently. Hence, radical formation (and propagation) is only efficient within this illuminated shell.

Table 3: Screening of the effect of mixing acetonitrile in benzene on the photoredox reaction. ${ }^{a}$

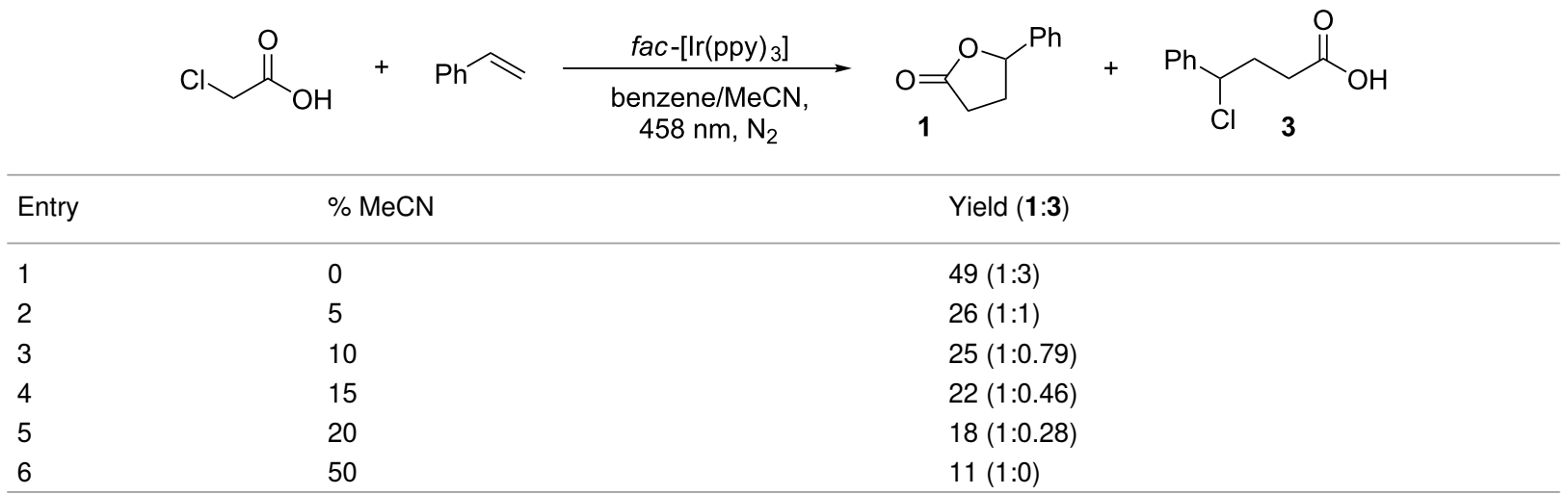

${ }^{a} \mathrm{~A}$ mixture of styrene $(0.02 \mathrm{M})$, monochloroacetic acid (5 equiv), fac-[ $\left.\operatorname{lr}(\mathrm{ppy})_{3}\right]$ in a mixture of benzene and acetonitrile $(2 \mathrm{~mL})$ was irradiated overnight under an $\mathrm{N}_{2}$ atmosphere with $458 \mathrm{~nm}$ LEDs. The yield was determined by ${ }^{1} \mathrm{H}$ NMR spectroscopy with trimethoxybenzene as external standard. 
We anticipated that in a flow setup using tubing with a small internal diameter $(0.71 \mathrm{~mm})$ the photocatalyzed reaction pathways could be more efficient. However, in this case, performing the reaction under flow conditions did not lead to better results. The reaction performed in a flow reactor led to a combined yield of $32 \%$ within 1 hour. Furthermore, as in a normal reactor, we also observed formation of precipitate in the flow setup, forming clusters of solids. These solids presumably consist of the oxidized or otherwise deactivated photocatalyst.

More insight into the selectivity for either the formation of the lactone or the ATRA reaction was obtained by screening a small substrate scope of para-substituted styrene derivatives in the photocatalyzed reaction with monochloroacetic acid using $f a c$ - $\left[\operatorname{Ir}(\text { ppy })_{3}\right]$ as the photocatalyst (Scheme 5). For electronpoor $p$-halogenated and $p$-trifluoromethylated styrenes no lactone formation took place in these reactions, and only the
Kharasch-addition product was observed. The benzylic radical resulting from radical addition to these styrene derivatives seems to be too electron poor for efficient oxidation induced cyclization, thus resulting in a Kharasch-type radical propagation reaction as the main pathway. Upon increasing the electron density by using 4-vinylanisole, we did see formation of the lactone product. When we used $p$-nitrostyrene, no formation of the desired products was observed at all.

Based on the results described above we propose the mechanism shown in Scheme 6, in which monochloroacetic acid oxidatively quenches the excited photocatalyst $\left(f a c-\left[\operatorname{Ir}(\mathrm{ppy})_{3}\right]^{*}\right)$. The thus obtained reduced monochloroacetic acid loses $\mathrm{Cl}^{-}$to give the carboxymethanide radical intermediate A. Addition of this species to styrene results in benzyl radical intermediate $\mathbf{B}$. From here two pathways are considered. Species $\mathbf{B}$ can be oxidized by the $\left[\operatorname{Ir}(\mathrm{ppy})_{3}\right]^{+}$species that is formed after oxida-

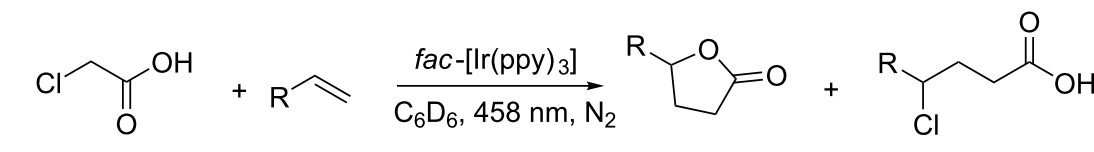

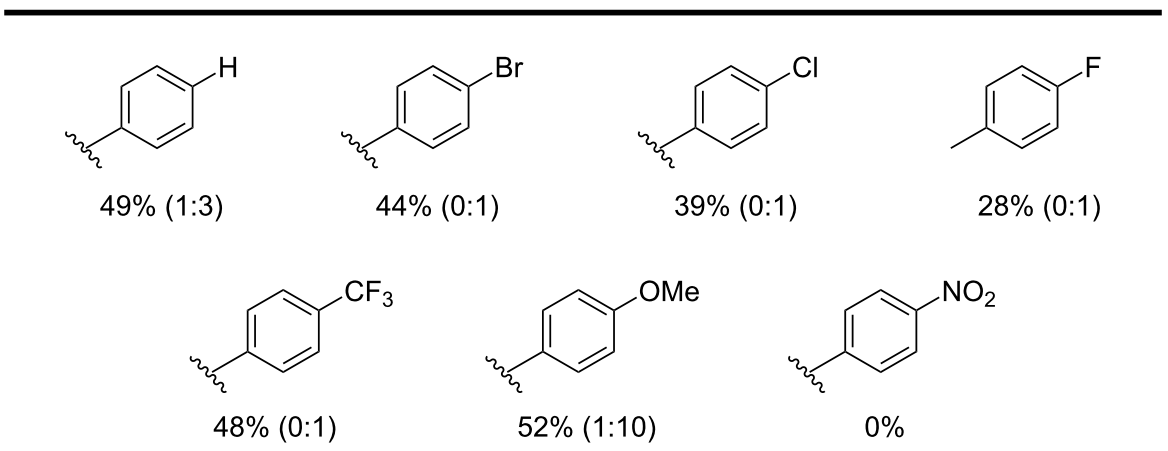

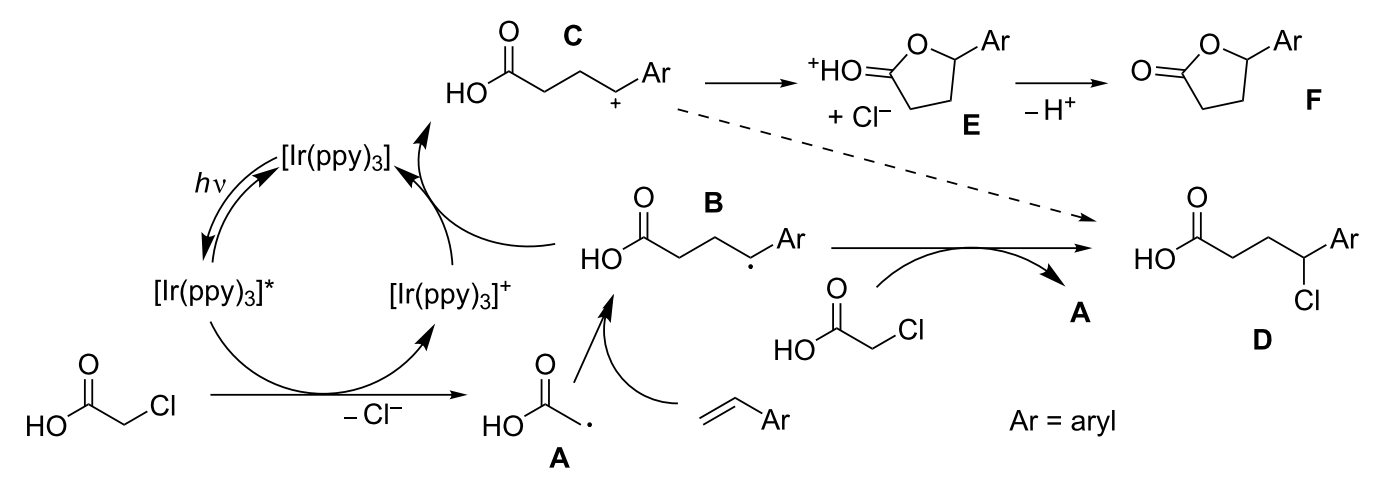


tive quenching to regenerate the ground-state photocatalyst together with the formation of the benzyl cation intermediate $\mathbf{C}$. Species $\mathbf{C}$ then cyclizes to give intermediate $\mathbf{E}$, which releases $\mathrm{H}^{+}$to form the lactone product $\mathbf{F}$. Alternatively, B forms the Kharasch-addition product $\mathbf{D}$ by chlorine atom abstraction from another monochloroacetic acid molecule, thus forming a new radical species $\mathbf{A}$. Capture of $\mathrm{Cl}^{-}$by intermediate $\mathbf{C}$ (dashed arrow) cannot be fully ruled out, but seems unlikely to compete with ring closure to $\mathbf{F}$ for entropic reasons.

All attempts to trap intermediate $\mathbf{C}$ using methanol or acetic acid as co-solvent (see Table 2) were unsuccessful and resulted in lower yields, especially in the case of methanol, likely due to the increased polarity of the reaction mixture. Additionally, to provide evidence for oxidative quenching, we tried trapping the carboxymethanide radical with TEMPO in benzene. We were surprised to see that instead we trapped the chloromethyl radical (Scheme 7) which was not expected in the absence of any base and with a relatively poorly oxidizing photoredox catalyst such as $f a c-\left[\operatorname{Ir}(\mathrm{ppy})_{3}\right]$. It is known that under acidic conditions TEMPO can disproportionate into [TEMPO ${ }^{+}$and TEMPO-H [54-56]. [TEMPO] ${ }^{+}\left(+0.25 \mathrm{~V}\right.$ vs $\mathrm{Fc} / \mathrm{Fc}^{+}$[56]) is a strong enough oxidant to oxidatively quench $\left[\operatorname{Ir}(\mathrm{ppy})_{3}\right]^{*}(-0.30 \mathrm{~V}$ vs $\left.\mathrm{Fc} / \mathrm{Fc}^{+}[34]\right)$. However, the oxidizing power of $\left[\operatorname{Ir}(\mathrm{ppy})_{3}\right]^{+}$ $(+0.77 \mathrm{~V}$ vs SCE$)$ is insufficient to oxidatively decarboxylate an acetate intermediate $(\approx+1.2 \mathrm{~V}$ vs SCE). Unexpected electron transfer pathways can be considered, such as the selfdecarboxylation that was previously observed for a $\left[\mathrm{Cl}_{3} \mathrm{CCO}_{2} \mathrm{H}\right]\left[\mathrm{O}_{2} \mathrm{CCl}_{3}\right]$ mixture [57].

Inspired by the result above on decarboxylative activation we anticipated its possibilities in cyclopropanation. The chloromethyl radical generation by photoredox catalysis is a useful strategy for cyclopropanation [58]. Most photoredox catalyzed, decarboxylative generations of carbon-centered radicals are based on the formation of "stabilized" $\alpha$-amino [59-65] or benzyl [66-70] radical species. However, the generation of unstabilized alkyl radical species is also known [71-74]. Based on these observations and considerations, we attempted to use monochloroacetic acid as a precursor for cyclopropanation. We have screened a series of strongly oxidizing photoredox catalysts and various alkenes, but unfortunately we were thus far unsuccessful in obtaining cyclopropane derivatives (see experimental section).

\section{Conclusion}

We have shown that it is possible to use monochloroacetic acid to form two types of radicals with visible light photoredox catalysis. The reductive formation of the carboxymethanide radical could be used for lactone formation with styrene. Benzene was found to be the best solvent for this reaction. However, the reaction is associated with some unsolved problems. The carboxylic acid group seems to be advantageous for the activation of monochloroacetic acid, but the apolar solvent in combination with formation of $\mathrm{HCl}$ is likely to cause catalyst deactivation/precipitation. This effect is more pronounced if electron-poor styrenes are used. We also found indications that a chloromethyl radical can be formed with photoredox catalysis from monochloroacetic acid, but we were not yet able to apply such reactions in a productive manner, such as in cyclopropanation reactions.

\section{Supporting Information}

\author{
Supporting Information File 1 \\ Experimental details. \\ [https://www.beilstein-journals.org/bjoc/content/ \\ supplementary/1860-5397-16-38-S1.pdf]
}

\section{Acknowledgements}

We would like to thank Ed Zuidinga for measuring mass spectra and Tijmen Bakker for recording the emission spectra of the light sources used in this work. We would like to thank Paul Kuijpers and Sander Woutersen for useful discussions regarding the IR spectroscopy measurements.

\section{Funding}

This research was supported by The Netherlands Organization for Scientific Research (NWO), the Holland Research School of Molecular Chemistry (HRSMC), the UvA Research Priority Area "Sustainable Chemistry" and the Advanced Research Center Chemical Building Blocks Consortium (ARC-CBBC project number 2019.021.A).

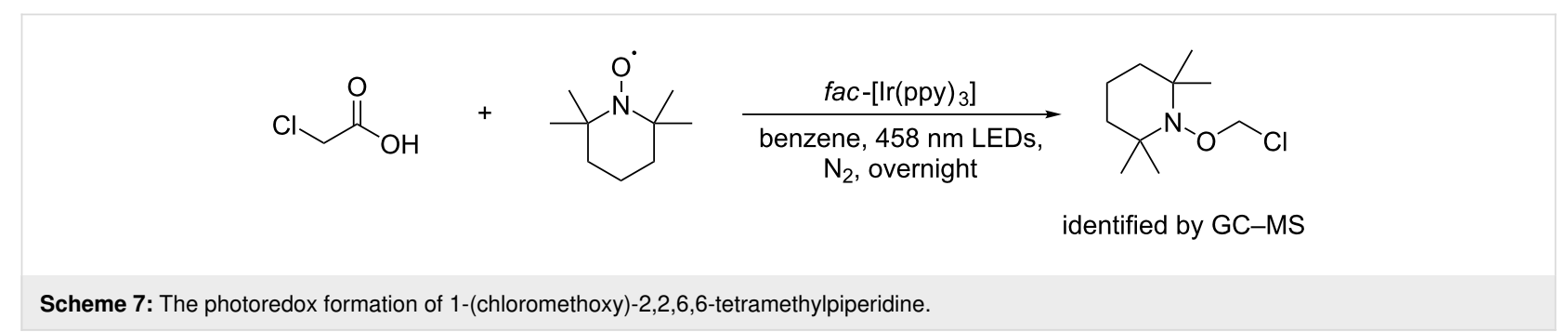




\section{ORCID ${ }^{\circledR}$ iDs}

Albert M. Brouwer - https://orcid.org/0000-0002-1731-3869

Bas de Bruin - https://orcid.org/0000-0002-3482-7669

\section{References}

1. Toğrul, H.; Arslan, N. Carbohydr. Polym. 2003, 54, 73-82. doi:10.1016/s0144-8617(03)00147-4

2. Joshi, G.; Naithani, S.; Varshney, V. K.; Bisht, S. S.; Rana, V.; Gupta, P. K. Waste Manage. (Oxford, U. K.) 2015, 38, 33-40. doi:10.1016/j.wasman.2014.11.015

3. Nwokonkwo, D. C.; Okafor, C. O. Int. J. Appl. Chem. 2016, 12, 67-74.

4. Product essay monochloroacetic acid, Kat Chem. http://www.kat-chem.hu/en/prod-bulletins/monoklorecetsav (accessed Nov 6, 2019).

5. Zeng, Y.; Li, Z.; Asselin, E. Ind. Eng. Chem. Res. 2015, 54, 3488-3497. doi:10.1021/acs.iecr.5b00320

6. Yang, L. M.; Jiang, N. N.; Zhao, Z. Y. Adv. Mater. Res. 2011, 396-398, 1711-1715. doi:10.4028/www.scientific.net/amr.396-398.1711

7. Li, W.; Chang, S.; Chen, X.; Qi, X.; Sun, H.-B. Asian J. Chem. 2014, 26, 3404-3406. doi:10.14233/ajchem.2014.17537

8. Maisonial, A.; Serafin, P.; Traïkia, M.; Debiton, E.; Théry, V.; Aitken, D. J.; Lemoine, P.; Viossat, B.; Gautier, A. Eur. J. Inorg. Chem. 2008, 298-305. doi:10.1002/ejic.200700849

9. Islamgulova, V. R.; Shitova, E. N.; Akhmerova, S. G.; Tomilov, A. P. Russ. J. Appl. Chem. 2002, 75, 1438-1440. doi:10.1023/a:1022276812235

10. Weiner, N. Org. Synth. 1938, 18, 50. doi:10.15227/orgsyn.018.0050

11. Stephenson, C.; Yoon, T.; MacMillan, D. W. C. Visible Light Photocatalysis in Organic Chemistry; Wiley-VCH: Weinheim, Germany, 2018. doi:10.1002/9783527674145

12. Chirila, A.; van Vliet, K. M.; Paul, N. D.; de Bruin, B. Eur. J. Inorg. Chem. 2018, 2251-2258. doi:10.1002/ejic.201800101

13. Chirila, A.; Brands, M. B.; de Bruin, B. J. Catal. 2018, 361, 347-360. doi:10.1016/j.jcat.2018.02.013

14. Chirila, A.; Gopal Das, B.; Paul, N. D.; de Bruin, B. ChemCatChem 2017, 9, 1413-1421. doi:10.1002/cctc.201601568

15. Otte, M.; Kuijpers, P. F.; Troeppner, O.; Ivanović-Burmazović, I.; Reek, J. N. H.; de Bruin, B. Chem. - Eur. J. 2014, 20, 4880-4884. doi:10.1002/chem.201400055

16. Paul, N. D.; Chirila, A.; Lu, H.; Zhang, X. P.; de Bruin, B. Chem. - Eur. J. 2013, 19, 12953-12958. doi:10.1002/chem.201301731

17. Hu, J.; Wang, J.; Nguyen, T. H.; Zheng, N. Beilstein J. Org. Chem. 2013, 9, 1977-2001. doi:10.3762/bjoc.9.234

18. Margrey, K. A.; Nicewicz, D. A. Acc. Chem. Res. 2016, 49, 1997-2006. doi:10.1021/acs.accounts.6b00304

19. Jin, Y.; Fu, H. Asian J. Org. Chem. 2017, 6, 368-385. doi:10.1002/ajoc.201600513

20. Cuthbertson, J. D.; MacMillan, D. W. C. Nature 2015, 519, 74-77. doi:10.1038/nature14255

21. Zhu, S.; Qin, J.; Wang, F.; Li, H.; Chu, L. Nat. Commun. 2019, 10, No. 749. doi:10.1038/s41467-019-08669-1

22. Wang, R.; Ma, M.; Gong, X.; Fan, X.; Walsh, P. J. Org. Lett. 2019, 21 , 27-31. doi:10.1021/acs.orglett.8b03394

23. Ghosh, I.; Marzo, L.; Das, A.; Shaikh, R.; König, B. Acc. Chem. Res. 2016, 49, 1566-1577. doi:10.1021/acs.accounts.6b00229

24. Ye, S.; Zheng, D.; Wu, J.; Qiu, G. Chem. Commun. 2019, 55, 2214-2217. doi:10.1039/c9cc00347a

25. Fukuzumi, S.; Mochizuki, S.; Tanaka, T. J. Phys. Chem. 1990, 94, 722-726. doi:10.1021/j100365a039
26. Narayanam, J. M. R.; Tucker, J. W.; Stephenson, C. R. J. J. Am. Chem. Soc. 2009, 131, 8756-8757. doi:10.1021/ja9033582

27. Poelma, S. O.; Burnett, G. L.; Discekici, E. H.; Mattson, K. M.; Treat, N. J.; Luo, Y.; Hudson, Z. M.; Shankel, S. L.; Clark, P. G.; Kramer, J. W.; Hawker, C. J.; Read de Alaniz, J. J. Org. Chem. 2016, 81, 7155-7160. doi:10.1021/acs.joc.6b01034

28. Barton, D. H. R.; Csiba, M. A.; Jaszberenyi, J. C. Tetrahedron Lett. 1994, 35, 2869-2872. doi:10.1016/s0040-4039(00)76646-9

29. Triandafillidi, I.; Kokotou, M. G.; Kokotos, C. G. Org. Lett. 2018, 20, 36-39. doi:10.1021/acs.orglett.7b03256

30. Li, X.; Ma, J.; Liu, G.; Fang, J.; Yue, S.; Guan, Y.; Chen, L.; Liu, X. Environ. Sci. Technol. 2012, 46, 7342-7349. doi:10.1021/es3008535

31. Brautzsch, M.; Kerzig, C.; Goez, M. Green Chem. 2016, 18 , 4761-4771. doi:10.1039/c6gc01113f

32. Goez, M.; Kerzig, C.; Naumann, R. Angew. Chem., Int. Ed. 2014, 53, 9914-9916. doi:10.1002/anie.201405693

33. Naumann, R.; Kerzig, C.; Goez, M. Chem. Sci. 2017, 8, 7510-7520. doi:10.1039/c7sc03514d

34. Doeven, E. H.; Zammit, E. M.; Barbante, G. J.; Francis, P. S.; Barnett, N. W.; Hogan, C. F. Chem. Sci. 2013, 4, 977-982. doi:10.1039/c2sc21707d

35. Prier, C. K.; Rankic, D. A.; MacMillan, D. W. C. Chem. Rev. 2013, 113, 5322-5363. doi:10.1021/cr300503r

36. Speight, J. Lange's Handbook Of Chemistry, 16th ed.; McGraw-Hill Education: New York, NY, USA, 2005.

37. Sideri, I. K.; Voutyritsa, E.; Kokotos, C. G. Org. Biomol. Chem. 2018, 16, 4596-4614. doi:10.1039/c8ob00725j

38. Theriot, J. C.; Lim, C.-H.; Yang, H.; Ryan, M. D.; Musgrave, C. B.; Miyake, G. M. Science 2016, 352, 1082-1086. doi:10.1126/science.aaf3935

39. Lim, C.-H.; Ryan, M. D.; McCarthy, B. G.; Theriot, J. C.; Sartor, S. M.; Damrauer, N. H.; Musgrave, C. B.; Miyake, G. M. J. Am. Chem. Soc. 2017, 139, 348-355. doi:10.1021/jacs.6b11022

40. Pearson, R. M.; Lim, C.-H.; McCarthy, B. G.; Musgrave, C. B.; Miyake, G. M. J. Am. Chem. Soc. 2016, 138, 11399-11407. doi:10.1021/jacs.6b08068

41. Ramsey, B. L.; Pearson, R. M.; Beck, L. R.; Miyake, G. M. Macromolecules 2017, 50, 2668-2674. doi:10.1021/acs.macromol.6b02791

42. Ryan, M. D.; Pearson, R. M.; French, T. A.; Miyake, G. M. Macromolecules 2017, 50, 4616-4622. doi:10.1021/acs.macromol.7b00502

43. Du, Y.; Pearson, R. M.; Lim, C.-H.; Sartor, S. M.; Ryan, M. D.; Yang, H.; Damrauer, N. H.; Miyake, G. M. Chem. - Eur. J. 2017, 23, 10962-10968. doi:10.1002/chem.201702926

44. Zhang, M.; Li, W.; Duan, Y.; Xu, P.; Zhang, S.; Zhu, C. Org. Lett. 2016, 18, 3266-3269. doi:10.1021/acs.orglett.6b01515

45. Kharasch, M. S.; Skell, P. S.; Fisher, P. J. Am. Chem. Soc. 1948, 70, 1055-1059. doi:10.1021/ja01183a053

46. The change in product ratio in polar solvents in favor of lactone product 1 could be due to nucleophilic substitution of $\mathrm{Cl}$ by the carboxylic acid of product 3. This does not occur in benzene (vide infra).

47. Wei, X.-J.; Boon, W.; Hessel, V.; Noël, T. ACS Catal. 2017, 7, 7136-7140. doi:10.1021/acscatal.7b03019

48. Sharma, U. K.; Gemoets, H. P. L.; Schröder, F.; Noël, T.; Van der Eycken, E. V. ACS Catal. 2017, 7, 3818-3823. doi:10.1021/acscatal.7b00840

49. Straathof, N. J. W.; Tegelbeckers, B. J. P.; Hessel, V.; Wang, X.; Noël, T. Chem. Sci. 2014, 5, 4768-4773. doi:10.1039/c4sc01982b 
50. Straathof, N. J. W.; Gemoets, H. P. L.; Wang, X.; Schouten, J. C.; Hessel, V.; Noël, T. ChemSusChem 2014, 7, 1612-1617. doi:10.1002/cssc.201301282

51. Tucker, J. W.; Zhang, Y.; Jamison, T. F.; Stephenson, C. R. J. Angew. Chem., Int. Ed. 2012, 51, 4144-4147. doi:10.1002/anie.201200961

52. Garlets, Z. J.; Nguyen, J. D.; Stephenson, C. R. J. Isr. J. Chem. 2014, 54, 351-360. doi:10.1002/ijch.201300136

53. Anselmo, M.; Basso, A.; Protti, S.; Ravelli, D. ACS Catal. 2019, 9, 2493-2500. doi:10.1021/acscatal.8b03875

54. Janiszewska, A. M.; Grzeszczuk, M. Electroanalysis 2004, 16, 1673-1681. doi:10.1002/elan.200303011

55. Israeli, A.; Patt, M.; Oron, M.; Samuni, A.; Kohen, R.; Goldstein, S. Free Radical Biol. Med. 2005, 38, 317-324. doi:10.1016/j.freeradbiomed.2004.09.037

56. Gerken, J. B.; Stahl, S. S. ACS Cent. Sci. 2015, 1, 234-243. doi:10.1021/acscentsci.5b00163

57. Valencia, D. P.; Astudillo, P. D.; Galano, A.; González, F. J. Org. Biomol. Chem. 2013, 11, 318-325. doi:10.1039/c2ob26961a

58. Guo, T.; Zhang, L.; Liu, X.; Fang, Y.; Jin, X.; Yang, Y.; Li, Y.; Chen, B.; Ouyang, M. Adv. Synth. Catal. 2018, 360, 4459-4463. doi:10.1002/adsc.201800761

59. Chen, Y.; Lu, P.; Wang, Y. Org. Lett. 2019, 21, 2130-2133. doi:10.1021/acs.orglett.9b00443

60. Rahman, M.; Mukherjee, A.; Kovalev, I. S.; Kopchuk, D. S.; Zyryanov, G. V.; Tsurkan, M. V.; Majee, A.; Ranu, B. C.; Charushin, V. N.; Chupakhin, O. N.; Santra, S. Adv. Synth. Catal. 2019, 361, 2161-2214. doi:10.1002/adsc.201801331

61. Garreau, M.; Le Vaillant, F.; Waser, J. Angew. Chem., Int. Ed. 2019, 58, 8182-8186. doi:10.1002/anie.201901922

62. Kammer, L. M.; Lipp, B.; Opatz, T. J. Org. Chem. 2019, 84, 2379-2392. doi:10.1021/acs.joc.8b02759

63. Cartwright, K. C.; Tunge, J. A. ACS Catal. 2018, 8, 11801-11806. doi:10.1021/acscatal.8b03282

64. Shu, C.; Mega, R. S.; Andreassen, B. J.; Noble, A.; Aggarwal, V. K. Angew. Chem., Int. Ed. 2018, 57, 15430-15434. doi:10.1002/anie.201808598

65. Hsieh, H.-W.; Coley, C. W.; Baumgartner, L. M.; Jensen, K. F.; Robinson, R. I. Org. Process Res. Dev. 2018, 22, 542-550. doi:10.1021/acs.oprd.8b00018

66. Guo, J.; Huang, G.-B.; Wu, Q.-L.; Xie, Y.; Weng, J.; Lu, G. Org. Chem. Front. 2019, 6, 1955-1960. doi:10.1039/c9qo00380k

67. Sakakibara, Y.; Ito, E.; Fukushima, T.; Murakami, K.; Itami, K. Chem. - Eur. J. 2018, 24, 9254-9258. doi:10.1002/chem.201802143

68. Chen, H.; He, Y.; Zhou, L. Org. Chem. Front. 2018, 5, 3240-3244. doi:10.1039/c8qo00970h

69. Guo, J.; Wu, Q.-L.; Xie, Y.; Weng, J.; Lu, G. J. Org. Chem. 2018, 83, 12559-12567. doi:10.1021/acs.joc.8b01849

70. Song, H.-T.; Ding, W.; Zhou, Q.-Q.; Liu, J.; Lu, L.-Q.; Xiao, W.-J. J. Org. Chem. 2016, 81, 7250-7255. doi:10.1021/acs.joc.6b01360

71. Tian, W.-F.; Hu, C.-H.; He, K.-H.; He, X.-Y.; Li, Y. Org. Lett. 2019, 21 , 6930-6935. doi:10.1021/acs.orglett.9b02539

72. Sherwood, T. C.; Li, N.; Yazdani, A. N.; Dhar, T. G. M. J. Org. Chem. 2018, 83, 3000-3012. doi:10.1021/acs.joc.8b00205

73. Ramirez, N. P.; Gonzalez-Gomez, J. C. Eur. J. Org. Chem. 2017, 2154-2163. doi:10.1002/ejoc.201601478

74. Johnston, C. P.; Smith, R. T.; Allmendinger, S.; MacMillan, D. W. C. Nature 2016, 536, 322-325. doi:10.1038/nature19056

\section{License and Terms}

This is an Open Access article under the terms of the Creative Commons Attribution License (https://creativecommons.org/licenses/by/4.0). Please note that the reuse, redistribution and reproduction in particular requires that the authors and source are credited.

The license is subject to the Beilstein Journal of Organic Chemistry terms and conditions:

(https://www.beilstein-journals.org/bjoc)

The definitive version of this article is the electronic one which can be found at:

doi: $10.3762 /$ bjoc. 16.38 